\title{
Are ipsilateral breast tumour invasive recurrences in young ( $\leqslant 40$ years) women more aggressive than their primary tumours?
}

\author{
B Sigal-Zafrani ${ }^{1,6}$, MA Bollet ${ }^{*, 2,6}$, G Antoni $^{3}$, A Savignoni ${ }^{3}$, A Vincent-Salomon', J-Y Pierga ${ }^{4}$, R Salmon $^{5}$, \\ $X$ Sastre-Garau' and A Fourquet ${ }^{2}$
}

'Department of Pathology, Institut Curie, Paris, France; '2Department of Radiation Oncology, Institut Curie, Paris, France; ${ }^{3}$ Department of Biostatistics, Institut Curie, Paris, France; ${ }^{4}$ Department of Medical Oncology, Institut Curie, Université René Descartes Paris 5, Paris, France; ${ }^{5}$ Department of Surgery, Institut Curie, Paris, France

The characteristics of ipsilateral breast tumour recurrences (IBTRs) relative to those of their primary tumours (PTs) remain scarcely studied. Of 70 young ( $\leqslant 40$ years) premenopausal women with IBTRs, we studied a series of 63 with paired histological data. Median follow-up since IBTR was 10 years. Rates of histological types, grades or hormonal receptors were not significantly different in PTs and in IBTRs. The concordance between IBTRs and their PTs was good for histological types. IBTRs with conserved histological types tended to occur more locally, but not significantly sooner than others. These IBTRs had good concordance for hormone receptors. In discordant cases there were as many losses as appearances of the receptors. The concordance was weak for grades, with equivalent numbers of IBTRs graded lower as higher than their PTs. The 10-year overall survival rate was $70 \%$. Neither the conservation of histological type, location, nor of the two combined were associated with deaths. Early ( $<2$ years) IBTRs, tended to be associated with poorer survival $(H R=2.24(0.92-5.4 I) ; P=0.08)$. IBTRs did not display features of higher aggressiveness than PTs. Neither clinical nor histological definition of a true recurrence could be established other than the conservation of the histological type. British Journal of Cancer (2007) 97, 1046- 1052. doi:I0.1038/sj.bjc.660399I www.bjcancer.com

Published online 18 September 2007

(c) 2007 Cancer Research UK

Keywords: breast cancer; local recurrence; breast-conserving treatment; young age

Breast-conserving treatments of early stage breast cancer exposes the patient to the risk of ipsilateral breast tumour recurrence (IBTR). The most important prognostic factor for local recurrence is the young age of the patient (Vrieling et al, 2003) and this remains true among young ( $<40$ years old), premenopausal women treated either by surgery first (Bollet et al, 2007) or by neoadjuvant chemotherapy (Oh et al, 2006). Many questions remain unanswered concerning the real nature of these ipsilateral breast tumour recurrences. We shall examine how different they are from primary tumours and whether there are clinical or histological factors to help distinguish between a re-growth of malignant cells not removed by surgery and not killed by radiotherapy (also called a true recurrence, TR) and a de novo malignancy arising from mammary epithelial cells of residual breast tissues (also known as new primary tumours, NP) (Haffty et al, 1993). Some have implied that ipsilateral breast tumour recurrences should display features of, at least as much aggressiveness (differentiation (Huang et al, 2002), ploidy (Haffty et al, 1993) and percentage of invasiveness (Haffty et al, 1993; Smith et al, 2000; Huang et al, 2002)) to qualify as true recurrences. We shall see whether biological evidence can be found to support this

*Correspondence: Dr MA Bollet, Department of Radiation Oncology, Institut Curie, 26, Rue d'Ulm, Paris 75005, France;

E-mail: marc.bollet@curie.net

${ }^{6}$ These two authors have contributed equally to this study.

Received 7 June 2007; revised 2 August 2007; accepted 14 August 2007; published online 18 September 2007 definition. Finally, we shall investigate whether the characteristics of ipsilateral breast tumour recurrences are associated with prognosis.

\section{PATIENTS AND METHODS}

Out of a previously described series of 209 premenopausal women, younger than 40 years old, treated at the Institut Curie between 1985 and 1995 for early breast cancers (clinical T1-2, N0-1 ; Sobin and Wittekind, 2002) with primary breast-conserving surgery and followed over a long period (median follow-up of 12 years), 70 patients were diagnosed with local recurrences (Bollet et al, 2007). We consider here a group of 63 patients for whom histological and immuno-histochemical data were available for both the primary tumour and the local relapse (some patients were not treated for their local relapse at the Institut Curie). We report here a study about the similarities between primary breast cancers and their local relapses in terms of histological and immuno-histochemical features according to the site of relapse and the time-lapse before relapse. Median age at diagnosis was 36 years $(23-40)$ with $57 \%$ of patients (36 patients) 35 year old or younger and $43 \%$ between 36 and 39 years old (27 patients). All patients were premenopausal at the time of the initial treatment. A family history indicating that at least one first- or second-degree relative with a history of breast cancer was present in $71 \%$ of patients ( 45 patients), absent in $27 \%$ (17 patients) and unknown in $2 \%$ (1 patient). 
Patients' characteristics were as follows: clinical tumour stage (Sobin and Wittekind, 2002) was T1 for 70\% (44 patients) and T2 for $30 \%$ (19 patients). N stage was N0 for $73 \%$ (50 patients), N1 for $21 \%$ (13 patients).

All the specimens were reviewed by the same qualified breast pathologist (BSZ). Histological classification of the infiltrating carcinomas was done according to the World Health Organization criteria and histological grades were scored according to Elston and Ellis (1991). The mitotic index was determined according to the number of mitoses per 10 high power fields (each field corresponded to a surface of $3.3 \mathrm{~mm}^{2}$ ), as low when $<11$, moderate when $(11-22)$ and high when $>22$ (Vincent-Salomon et al, 2004). Hormonal receptors were positive if they showed staining of either oestradiol receptors (ER) or progesterone receptors in at least $10 \%$ of invasive tumour cells by immunohistochemistry.

Treatments of the primary tumour consisted, for all patients, in surgery with breast-conserving procedures as the first treatment. The quality of the surgical margin was stated as wide $(>3 \mathrm{~mm})$ in 40 patients $(63 \%)$, close $(\leqslant 3 \mathrm{~mm})$ in $14(22 \%)$, involved with ductal carcinoma in situ in four $(6 \%)$, involved with invasive carcinoma in five (8\%). The reasons for the absence of re-excision were not always specified. When they were, it was because of the patient's choice not to undergo a new surgical procedure that could have been a mastectomy.

All patients received post-operative radiotherapy with a median dose of $54 \mathrm{~Gy}(45-62)$ to the breast. A boost to the tumorectomy bed was performed for $68 \%$ (36 patients) of the women with a median dose of $16 \mathrm{~Gy}(2-25)$. The median total dose to the tumorectomy bed was $62 \mathrm{~Gy}(52-76)$. There was no protocol to boost all young patients with negative surgical margins at that time and some of the patients reported in this series were accrued in the EORTC boost trial that randomised from 1989 to 1996 between boost and no boost (Bartelink et al, 2001; Vrieling et al, 2003; Antonini et al, 2006). In the case of positive surgical margins, a radiotherapy boost of generally $20-28 \mathrm{~Gy}$ was added to the wholebreast irradiation. For patients who were not participating in the European Organisation for Research and Treatment of Cancer randomised trial, a boost of $10-16 \mathrm{~Gy}$ was added in the case of aggressive histological features (unsatisfactory margins, high histological grade, high proliferation index, absence of hormone receptors).

Systemic treatments were given in $30 \%$ (63 patients) of the women. At the time of treatment, the protocol for premenopausal women consisted of anthracycline-based polychemotherapy (usually six cycles of 5-fluorouracil, doxorubicin, cyclophosphamide) without hormone therapy.

\section{Statistics}

Comparisons of pathological characteristics between primary tumours and ipsilateral breast tumour recurrences were performed by McNemar $\chi^{2}$ paired analysis that tests the hypothesis that, among discordant cases, the evolution was more often of one kind than another. For instance, when applied to oestradiol receptors, there was a significant difference between the numbers of cases with a loss of ER and those with an appearance of ER (ER - in PT and ER + in IBTR). When the analysed pathological feature had more than two classes, analysis was downsized to a $2 \times 2$ table.

Differences in qualitative assessments between the two groups of patients were tested by Fisher's exact test or the $\chi^{2}$-test, while differences in quantitative measurements were tested by either the Student's $t$-test or Kruskal-Wallis test (depending on the distribution characteristics). Median follow-up was calculated using the reverse Kaplan-Meier estimator (Kaplan and Meier, 1958). Overall survival was defined as the lapse of time from the date of ipsilateral breast tumour recurrence to the date of death. Distant relapse-free survival was defined from the date of ipsilateral breast tumour recurrence to the date of diagnosis of distant relapse or death. Overall and distant relapse-free survivals were estimated with the Kaplan-Meier technique (Kaplan and Meier, 1958). Cox proportional hazards regression models were used to estimate the effects of the type of ipsilateral breast tumour recurrences on prognosis. Estimates of effects are presented as hazard ratios with their associated $95 \%$ confidence intervals. A higher hazard ratio is associated with an increased risk of event (death or metastasis).

All concordance tests were calculated according to Cohen's Kappa. A kappa value $<0.5$ is considered weak, $0.5-0.7$ fair, and $>0.7$ is considered very good concordance. The level of statistical significance was 0.05 . The concordance tests were always assessed for the whole group of patients and in the two different subpopulations according to the lapse of time of occurrence of the local relapse from the first treatment of the primary tumour (within the first 5 years or later) or to the site of the local recurrence with respect to the primary tumour (same quadrant or different quadrant).

\section{RESULTS}

Median time-lapse between the primary tumour and its ipsilateral breast tumour recurrence was 43 months (3-158). Median followup since ipsilateral breast tumour recurrence was 10 years $(1-18)$.

Histological details of both the primary tumour and its ipsilateral breast tumour recurrence are given in Table 1. In summary, the rates of histological types, grades (and their components) or hormonal receptors were not statistically different in the primary tumours from the ipsilateral breast tumour recurrences.

Ipsilateral breast tumour recurrences occurred in the index quadrant, the one where the primary tumour had arisen, in $70 \%$ (44 patients), in a different quadrant in $27 \%$ (17 patients) and in $3 \%$ of cases (two patients) the relative locations were unknown. The mean time-lapse before occurrence of the ipsilateral breast tumour recurrence was not significantly different in the case of a recurrence at the index quadrant or not (respectively 55 vs 53 months; $P=0.8$ ). The rate of ipsilateral breast tumour recurrences occurring within the first 2 years was not significantly higher for those that had recurred at the index quadrant than for the others (18 vs $12 \%$; $P=0.72$ ).

\section{Concordance tests}

Histological types of infiltrating carcinomas As represented in Table 2 there was a good concordance with $94 \%$ of cases (59 patients out of 63) with conservation of the histological types $\kappa$ 0.72. The ipsilateral breast tumours that shared their primary tumour's histological types tended to occur more locally than those with a different histological type (rate of recurrence in the index quadrant of 75 vs $25 \% ; P=0.07$ ) but not statistically sooner (median time-lapse before occurrence of 41 vs 71 months; $P=0.36)$.

In 45 cases $(71 \%)$ ipsilateral breast tumour recurrences shared both the same histological type and the same location (index quadrant) with their primary tumours. These ipsilateral breast tumour recurrences did not occur significantly sooner than the others (median time lapse of 38 vs 54 months; $P=0.34$ ).

In 33 cases out of 61 cases for which data were available (52\%), the ipsilateral breast tumour recurrences had occurred not only with a conserved histological type, but also with features of equal or lesser differentiation (loss of hazard ratio, higher histological grade) than their primary tumours. These cases did not occur significantly neither more locally (rate of recurrence in the index quadrant of 81 vs $61 \% ; P=0.15$ ) nor sooner (median time lapse of 37 vs 51 months; $P=0.19$ ) than others. 
Table I Patients' and tumours' characteristics

\begin{tabular}{|c|c|c|c|c|c|}
\hline & \multicolumn{2}{|c|}{ Primary tumour } & \multicolumn{2}{|c|}{ IBTR } & \multirow[b]{2}{*}{$P$} \\
\hline & $\mathbf{N}$ & $\%$ & $\mathbf{N}$ & $\%$ & \\
\hline Infiltrating carcinoma $£$ & \multicolumn{2}{|c|}{$\mathrm{DM}=0$} & \multicolumn{2}{|c|}{$\mathrm{DM}=0$} & । \\
\hline Ductal & 55 & 87 & 55 & 87 & \\
\hline Lobular & 4 & 6 & 6 & 10 & \\
\hline Other & 4 & 6 & 2 & 3 & \\
\hline Histological grade & \multicolumn{2}{|c|}{$\mathrm{DM}=4$} & \multicolumn{2}{|c|}{$D M=3$} & I \\
\hline 1000 & 22 & 37 & 16 & 27 & \\
\hline 2 & 23 & 39 & 35 & 58 & \\
\hline 3 & 14 & 24 & 9 & 15 & \\
\hline Tubule formation & \multicolumn{2}{|c|}{$\mathrm{DM}=0$} & & & I \\
\hline 1.2 & 15 & 24 & 16 & 25 & \\
\hline 3 & 48 & 76 & 47 & 75 & \\
\hline Nuclear polymorphism & \multicolumn{2}{|c|}{$\mathrm{DM}=0$} & \multicolumn{2}{|c|}{$\mathrm{DM}=0$} & । \\
\hline 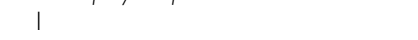 & 10 & 16 & 9 & 14 & \\
\hline 2 & 42 & 67 & 43 & 68 & \\
\hline 3 & 11 & 17 & 11 & 17 & \\
\hline Mitoses per 10 HPF & \multicolumn{2}{|c|}{$\mathrm{DM}=4$} & \multicolumn{2}{|c|}{$\mathrm{DM}=3$} & 0.48 \\
\hline$[0-10]$ & 40 & 68 & 40 & 67 & \\
\hline$[||-2 \mid]$ & 11 & 19 & 14 & 23 & \\
\hline$\geqslant 22$ & 8 & 14 & 6 & 10 & \\
\hline Oestradiol receptors & \multicolumn{2}{|c|}{$\mathrm{DM}=0$} & \multicolumn{2}{|c|}{$\mathrm{DM}=0$} & 0.43 \\
\hline Positive ( $\geqslant 10 \%)$ & 41 & 65 & 45 & 71 & \\
\hline Negative & 22 & 35 & 18 & 29 & \\
\hline Progesterone receptors & \multicolumn{2}{|c|}{$\mathrm{DM}=0$} & \multicolumn{2}{|c|}{$\mathrm{DM}=0$} & । \\
\hline Positive $(\geqslant 10 \%)$ & 42 & 67 & 41 & 65 & \\
\hline Negative & 21 & 33 & 22 & 35 & \\
\hline Hormone receptors & & & & & I \\
\hline Positive (either ER or PR $\geqslant 10 \%$ ) & 49 & 78 & 50 & 79 & \\
\hline Negative (both ER and PR < $10 \%$ ) & 14 & 22 & 13 & 21 & \\
\hline
\end{tabular}

$\mathrm{ER}=$ oestradiol receptors; $\mathrm{HPF}=$ high power field; $\mathrm{IBTR}=$ ipsilateral breast tumour recurrences; $\mathrm{PR}=$ progesterone receptor

Table 2 Comparison between pathological characteristics between PT and their ipsilateral breast tumour recurrences

\begin{tabular}{lccc}
\hline & \multicolumn{2}{c}{ Ipsilateral breast tumour recurrences } \\
\cline { 2 - 4 } $\begin{array}{l}\text { Histological type } \\
\text { of the infiltrating } \\
\text { carcinomas paired } \boldsymbol{\chi}^{\mathbf{2}} \\
\mathbf{( M c N e m a r} \text { test)= }\end{array}$ & & & \\
$\boldsymbol{\kappa}=\mathbf{0 . 7 2}$ & Ductal & Lobular & Mucinous \\
\hline Primary & 53 & 2 & \\
$\quad$ Ductal & 0 & 4 & 0 \\
$\quad$ Lobular & & & \\
Tumours & 0 & 0 & 2 \\
$\quad$ Mucinous & 2 & 0 & 0 \\
\hline Other & & & \\
\hline
\end{tabular}

$\mathrm{PT}=$ primary tumours

Sub-analysis of IBTR with conserved histological types (59 pairs) As represented in Table 3, provided that only conserved histological types were studied, the concordance between primary tumours and their local recurrences was weak for progesterone ( $\kappa$ 0.47), fair for oestradiol ( $\kappa 0.52$ ) and good for hormone ( $\kappa 0.85$ ) receptors. In the case of discordant cases, there was no statistically significant difference between changes, whether loss or appearance of the receptors.

Of the 54 pairs for which both the primary tumours and the ipsilateral breast tumour recurrences were histologically graded, the grades remained the same in 21 patients (39\%), weak concordance ( $\kappa$ 0.03). There was no statistically significant difference between patients for whom the IBTR was graded higher and those for whom it was graded lower than the primary tumour (17 vs 16 patients; $P=0.86$ ).

\section{Prognostic implications for the conservation of location, histological type or both on overall survival}

Rates of 5- and 10-year overall survivals were respectively $79 \%$ $(69-90)$ and $70 \%(59-84)$.

Neither the conservation of the histological type in the ipsilateral breast tumour recurrence (hazard ratio $=1.27 \quad(0.29-5.56)$; $P=0.75$ ), nor the conservation of location with ipsilateral breast tumour recurrence occurring at the index quadrant (hazard ratio $=1.13(0.43-2.95) ; P=0.8)$, nor the two combined, that is conservation of both histological type and location versus the others (hazard ratio $=1.07(0.43-2.7) ; P=0.88)$ nor those with conserved histological types and equal or lesser differentiation (hazard ratio $=2.08(0.85-5.2) ; P=0.11)$ were statistically associated with deaths. Early ipsilateral breast tumour recurrences, defined as occurring within the first 2 years, tended to be associated with a higher rate of death (hazard ratio $=2.24(0.92-$ 5.41); $P=0.08$ ) than late recurrences. When comparing both the tumours and their ipsilateral breast tumour recurrences according to the free interval with a cutoff at 2 years, the only statistically significant differences were that primary tumours associated with early ipsilateral breast tumour recurrences (IBTRs) were more proliferating than the others and that early IBTRs (occurring within the first 2 years) had a higher degree of nuclear polymorphism than late IBTRs, as shown in Table 4.

\section{DISCUSSION}

The occurrence of an ipsilateral breast tumour recurrence is associated with poor prognosis because of the potential risk of lethality from its propensity to yield metastases (Clarke et al, 2005).

In this study of a homogeneous group of young ( $\leqslant 40$ years old) patients, we did not find that, per se, ipsilateral breast tumour recurrences display features of higher aggressiveness than primary tumours (Table 1). All features were highly comparable between the two groups of tumours.

In some cases, the occurrence of an ipsilateral breast tumour recurrence can also reflect the evolution of the primary tumour and thus its resistance to the adjuvant therapies used in the first instance: that is radiotherapy with or without systemic treatments. These ipsilateral breast tumour recurrences are also called true recurrences, in opposition to new primaries. Their definition according to clinical and histological criteria remains a wild dream. All authors agree on a basic definition of a new primary that is, an ipsilateral breast tumour recurrence with a different histological type from its primary tumour (Haffty et al, 1993; Touboul et al, 1999; Smith et al, 2000; Huang et al, 2002; Komoike et al, 2005). Our series showed a good concordance of the histological type in the ipsilateral breast tumour recurrence.

Most authors have also proposed that location would help distinguish the two - with ipsilateral breast tumour recurrences occurring away from the index quadrant more prone to be new primaries (Fisher et al, 1986; Haffty et al, 1993; Smith et al, 2000; Huang et al, 2002). This was confirmed in our series where ipsilateral breast tumour recurrences that had conserved their 
Table 3 Comparison of pathological characteristics between PT and their ipsilateral breast tumour recurrences provided that they share the same histological types (59 pairs of PT/IBTR)

Ipsilateral breast tumour recurrence

Oestradiol receptors McNemar's test $=0.39 \kappa=0.52$

Negative Positive

\section{Primary tumour \\ Negative}

Positive

$\begin{array}{rr}12 & 8 \\ 4 & 35\end{array}$

Ipsilateral breast tumour recurrence

Progesterone receptors McNemar's test $=\mathbf{I} \kappa=0.47$

Negative Positive

Primary tumour
Negative

Positive

13

7

7

32

Ipsilateral breast tumour recurrence

Hormone receptors McNemar's test $=I \kappa=0.85$

Negative Positive

Primary tumour

Negative

Positive

II

$1 \quad 45$

Ipsilateral breast tumour recurrence

Histological grade $(D M=5)$ McNemar's test $=0.86 \kappa=0.03$

Grade I $\quad$ Grade 2

Grade 3

Primary tumour

Grade I

Grade 2

Grade 3

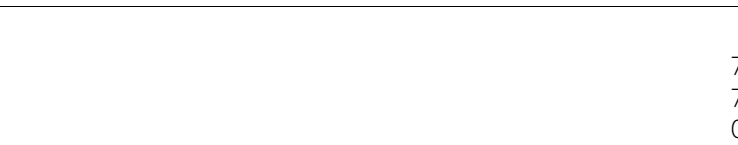

\begin{tabular}{lcc} 
Mitotic index (DM $=\mathbf{5})$ McNemar's test $=\mathbf{0 . 6 3} \boldsymbol{\kappa}=\mathbf{0 . 3 3}$ & Low & Moderate \\
\hline Primary tumour & & High \\
Low & 31 & 3 \\
Moderate & 4 & 5 \\
High & 3 & 3
\end{tabular}

Ipsilateral breast tumour recurrence

Nuclear polymorphism $(D M=0)$ McNemar's test $=0.6 \mathrm{I} \kappa=0.33$

\begin{tabular}{ccc}
\hline Low & Moderate & High \\
\hline & 3 & \\
2 & 34 & 1 \\
0 & 4 & 5 \\
& & 5
\end{tabular}

Primary tumour

Low

Moderate

High

Ipsilateral breast tumour recurrence

Tubule formation $(D M=0)$ McNemar's test $=I \kappa=0.12$

\begin{tabular}{ccc}
\hline Low & Moderate & High \\
0 & 2 & \\
0 & 4 & 8 \\
1 & 9 & 34 \\
\hline
\end{tabular}

\footnotetext{
Primary tumour

Low

Moderate

High
}

primary tumours' histological types tended to arise more often in the index quadrant than others. When addressing only ipsilateral breast tumour recurrences with conserved histological types, we showed a good concordance with their primary tumours in terms of hormonal receptors but the absence of any concordance in terms of histological grade and its components. Bearing in mind the inter-observer disagreement (Frierson et al, 1995; Robbins et al, 1995), there is always the concern that it could reflect an intra-observer variability in the definition of the histological grade.
The question remains whether the assumption that the definition of true recurrences could rely on the possibility that true recurrences show features of lesser differentiation than their primary tumours. To address it, we first looked at discordant cases in terms of histological grade. There was no sign that the evolution was more prone to be towards more aggressiveness than less. Secondly, ipsilateral breast tumour recurrences with conserved histological types with features of equal or lesser differentiation than their primary tumours did not occur significantly more locally. 
Table 4 Comparison of pathological features of primary tumours and of IBTR according to the free interval between the two (within or after 2 years)

\begin{tabular}{|c|c|c|c|c|c|c|c|c|c|c|}
\hline & \multicolumn{5}{|c|}{ Primary tumour } & \multicolumn{4}{|c|}{ IBTR } & \multirow[b]{3}{*}{$P$} \\
\hline & \multicolumn{2}{|c|}{ Early $(N=52)$} & \multicolumn{2}{|c|}{ Late $(N=I I)$} & \multirow[b]{2}{*}{$P$} & \multicolumn{2}{|c|}{ Early $(N=52)$} & \multicolumn{2}{|c|}{ Late $(N=I I)$} & \\
\hline & $\mathbf{N}$ & $\%$ & $\mathbf{N}$ & $\%$ & & $\mathbf{N}$ & $\%$ & $\mathbf{N}$ & $\%$ & \\
\hline Infiltrating carcinoma & & & & & 0.15 & & & & & 0.6 \\
\hline Ductal & 47 & 90 & 8 & 73 & & 46 & 88 & 9 & 82 & \\
\hline Lobular & 2 & 4 & 2 & 18 & & 4 & 8 & 2 & 18 & \\
\hline Other & 3 & 6 & 1 & 9 & & 2 & 4 & 0 & 0 & \\
\hline Histological grade & & & & & 0.18 & & & & & 0.2 \\
\hline 1 & 20 & 41 & 2 & 20 & & 15 & 30 & I & 10 & \\
\hline 2 & 20 & 41 & 3 & 30 & & 29 & 58 & 6 & 60 & \\
\hline 3 & 9 & 18 & 5 & 50 & & 6 & 12 & 3 & 30 & \\
\hline Tubule formation & & & & & 0.06 & & & & & 0.8 \\
\hline 1.2 & 15 & 29 & 0 & 0 & & 14 & 27 & 2 & 18 & \\
\hline 3 & 37 & 71 & $\mid 1$ & 100 & & 38 & 73 & 9 & 82 & \\
\hline Nuclear polymorphism & & & & & 0.13 & & & & & 0.005 \\
\hline I r t r t & 8 & 15 & 2 & 18 & & 8 & 15 & I & 9 & \\
\hline 2 & 37 & 71 & 5 & 45 & & 39 & 75 & 4 & 36 & \\
\hline 3 & 7 & 13 & 4 & 36 & & 5 & 10 & 6 & 55 & \\
\hline Mitoses per $10 \mathrm{HPF}^{\mathrm{a}}$ & & & & & 0.02 & & & & & 0.15 \\
\hline$[0-10]$ & 37 & 76 & 3 & 30 & & 36 & 72 & 4 & 40 & \\
\hline$[||-2 \mid]$ & 7 & 14 & 4 & 40 & & 10 & 20 & 4 & 40 & \\
\hline$\geqslant 22$ & 5 & 10 & 3 & 30 & & 4 & 8 & 2 & 20 & \\
\hline Oestradiol receptors & & & & & 0.5 & & & & & 0.3 \\
\hline Positive & 35 & 67 & 6 & 55 & & 39 & 75 & 6 & 55 & \\
\hline Negative & 17 & 33 & 5 & 45 & & 13 & 25 & 5 & 45 & \\
\hline Progesterone receptors & & & & & 0.8 & & & & & 0.18 \\
\hline Positive & 34 & 65 & 8 & 73 & & 36 & 69 & 5 & 45 & \\
\hline Negative & 18 & 35 & 3 & 27 & & 16 & 31 & 6 & 55 & \\
\hline Hormone receptors & & & & & 0.7 & & & & & 0.22 \\
\hline Positive & 41 & 79 & 8 & 73 & & 43 & 83 & 7 & 64 & \\
\hline Negative & || & 21 & 3 & 27 & & 9 & 17 & 4 & 36 & \\
\hline
\end{tabular}

IBTR $=$ ipsilateral breast tumour recurrences. ${ }^{a} \mathrm{HPF}=$ high power field. Bold values are statistically significant $P$-values.

The arguments to oppose this theoretical assumption (that true recurrences display at most equal but not higher differentiation than their primaries) are twofold. First, some adjuvant treatments such as chemotherapy could electively kill the most undifferentiated clones from the primary tumour and thus select those of higher differentiation, resistant to chemotherapy. The equivalent has already been shown in some studies where either the clonal heterogeneity found in the primary tumours (Teixeira et al, 1996) or the amount of their chromosomal alterations (Kuukasjarvi et al, 1997) were reduced in their metastases. Second, the chronological order of the discovery of two breast cancers with clonal homology does not forcefully reflect the paternity of the first over the second because a tumour with few alterations can be occult for years following the removal of a more deranged derivative. This has been inferred in the case of bladder cancer from the study of several tumours removed from the same patient over a long period of time (van Tilborg et al, 2000). Beside these arguments, the absence of a trend for a progression of grade between different stages of the breast cancer has already been shown by Millis et al (1998) both from ductal carcinoma in-situ to invasive ductal carcinoma and from invasive ductal carcinoma to axillary lymph nodes, local (ipsilateral breast tumour recurrences excluded) or distant recurrences.

Contrary to others (Haffty et al, 1993; Goldstein et al, 2005; Vicini et al, 2007), we found no indication that tumours more prone to be true recurrences because of conserved histological type, location or both, recur sooner or are deadlier than the others. The same applied to the conservation of histological type and features of equal or lesser differentiation. On the other hand, we confirmed the notion that early recurrences, that is occurring within the first 2 years, are associated with more deaths than late ones (Fourquet et al, 1989; Fisher et al, 1991; Whelan et al, 1994; Veronesi et al, 1995; Haffty et al, 1996; Fredriksson et al, 2002). In our study the group of patients with early recurrences had primary tumours significantly more proliferating and ipsilateral breast tumour recurrences with a higher degree of nuclear polymorphism than the group of patients with late recurrences.

The main drawback of this study is the relatively small size of our series under-powering the possibility of revealing real associations between the assessed factors. We conclude however that the definition of true recurrences according to clinical and histological criteria should rely solely on the conservation of the histological type with the added information brought by the location. There is no indication that true recurrences should have features of equal or lesser differentiation than their primary tumours.

However, because of the overwhelmingly high rate of the ductal histological type among breast cancers, there is need to improve the definition of true recurrences by using new biological tools of clonal relation such as pan-genomic profiles (Waldman et al, 
2000), loss of heterozygosity (Schlechter et al, 2004; Vicini et al, 2007), p53 mutation analysis (van der Sijp et al, 2002) or the inactivation of the X chromosome (Shibata et al, 1996). Caution is however still needed as some of these techniques conclude that only $65 \%$ of clonally related ipsilateral breast tumour recurrences have the same histological types as their primary tumours (Vicini et al, 2007).

We hope that a better distinction of true recurrences will open new perspectives. So far, very little is known about the differential or similarity of the pan-genomic expression or nature of both new primaries and IBTRs. Kreike et al (2006) reported a gene expression analysis of $18000 \mathrm{cDNAs}$ on nine pairs of primary breast cancer with their ipsilateral breast recurrences in women who were younger than 51 years old at the time of their initial breast-conserving therapy. Paired-data analysis showed no set of genes that was consistently different in expression between primary tumours and local recurrences. Better focusing on true recurrences only and comparing them in detail with their primary tumours, could hopefully reveal possible clonal selections of cells endowed with attributes of either radio-resistance or aggressiveness. Another route that has still scarcely been explored is the search for a transcriptomic signature to predict the risk of local recurrence after breast-conserving treatment (Kreike et al, 2006; Nuyten et al, 2006). Here also, a better distinction between new

\section{REFERENCES}

Antonini N, Jones H, Horiot JC, Poortmans P, Struikmans H, den Bogaert WV, Barillot I, Fourquet A, Jager J, Hoogenraad W, Collette L, Pierart M, Hart G, Bartelink H (2006) Effect of age and radiation dose on local control after breast conserving treatment: EORTC trial 22881-10882. Radiother Oncol 82: 265-271

Bartelink H, Horiot JC, Poortmans P, Struikmans H, Van den Bogaert W, Barillot I, Fourquet A, Borger J, Jager J, Hoogenraad W, Collette L, Pierart M (2001) Recurrence rates after treatment of breast cancer with standard radiotherapy with or without additional radiation. $N$ Engl J Med 345: $1378-1387$

Bollet MA, Sigal-Zafrani B, Mazeau V, Savignoni A, de la Rochefordiere A, Vincent-Salomon A, Salmon R, Campana F, Kirova YM, Dendale R, Fourquet A (2007) Age remains the first prognostic factor for locoregional breast cancer recurrence in young ( $<40$ years) women treated with breast conserving surgery first. Radiother Oncol 82: 272-280

Clarke M, Collins R, Darby S, Davies C, Elphinstone P, Evans E, Godwin J, Gray R, Hicks C, James S, MacKinnon E, McGale P, McHugh T, Peto R, Taylor C, Wang Y (2005) Effects of radiotherapy and of differences in the extent of surgery for early breast cancer on local recurrence and 15-year survival: an overview of the randomised trials. Lancet 366: 2087-2106

Elston CW, Ellis IO (1991) Pathological prognostic factors in breast cancer. I. The value of histological grade in breast cancer: experience from a large study with long-term follow-up. Histopathology 19: 403-410

Fisher B, Anderson S, Fisher ER, Redmond C, Wickerham DL, Wolmark N, Mamounas EP, Deutsch M, Margolese R (1991) Significance of ipsilateral breast tumour recurrence after lumpectomy. Lancet 338: 327-331

Fisher ER, Sass R, Fisher B, Gregorio R, Brown R, Wickerham L (1986) Pathologic findings from the National Surgical Adjuvant Breast Project (protocol 6). II. Relation of local breast recurrence to multicentricity. Cancer 57: $1717-1724$

Fourquet A, Campana F, Zafrani B, Mosseri V, Vielh P, Durand JC, Vilcoq JR (1989) Prognostic factors of breast recurrence in the conservative management of early breast cancer: a 25 -year follow-up. Int J Radiat Oncol Biol Phys 17: 719-725

Fredriksson I, Liljegren G, Arnesson LG, Emdin SO, Palm-Sjovall M, Fornander T, Holmqvist M, Holmberg L, Frisell J (2002) Local recurrence in the breast after conservative surgery - a study of prognosis and prognostic factors in 391 women. Eur J Cancer 38: 1860-1870

Frierson Jr HF, Wolber RA, Berean KW, Franquemont DW, Gaffey MJ, Boyd JC, Wilbur DC (1995) Interobserver reproducibility of the Nottingham modification of the Bloom and Richardson histologic grading scheme for infiltrating ductal carcinoma. Am J Clin Pathol 103: $195-198$ primaries and true recurrences is needed to perform a supervised study according to the occurrence of true recurrences only and not of all ipsilateral breast tumour recurrences.

\section{CONCLUSION}

Ipsilateral breast tumour recurrences did not display features of higher aggressiveness than primary tumours. There was no indication that tumours more prone to be true recurrences because of conserved histological type, location or both, recur sooner or are deadlier than the others. No clinical nor histological definition of a true recurrence could be established other than the conservation of the histological type.

\section{ACKNOWLEDGEMENTS}

We thank all the members of the Groupe Sein at the Institut Curie for their participation in the care of the patients. We also thank Danièle Chazal and Claudie Gallet for processing the pathological specimens and Chantal Gautier for managing the data. This study was financed by a grant from the Comité de Paris de la Ligue Nationale de Lutte contre le Cancer 75/00-RS/41.
Goldstein NS, Vicini FA, Hunter S, Odish E, Forbes S, Kraus D, Kestin LL (2005) Molecular clonality determination of ipsilateral recurrence of invasive breast carcinomas after breast-conserving therapy: comparison with clinical and biologic factors. Am J Clin Pathol 123: 679-689

Haffty BG, Carter D, Flynn SD, Fischer DB, Brash DE, Simons J, Ziegler AM, Fischer JJ (1993) Local recurrence versus new primary: clinical analysis of 82 breast relapses and potential applications for genetic fingerprinting. Int J Radiat Oncol Biol Phys 27: 575-583

Haffty BG, Reiss M, Beinfield M, Fischer D, Ward B, McKhann C (1996) Ipsilateral breast tumor recurrence as a predictor of distant disease: implications for systemic therapy at the time of local relapse. J Clin Oncol 14: $52-57$

Huang E, Buchholz TA, Meric F, Krishnamurthy S, Mirza NQ, Ames FC, Feig BW, Kuerer HM, Ross MI, Singletary SE, McNeese MD, Strom EA, Hunt KK (2002) Classifying local disease recurrences after breast conservation therapy based on location and histology: new primary tumors have more favorable outcomes than true local disease recurrences. Cancer 95: 2059-2067

Kaplan EL, Meier P (1958) Nonparametric estimation from incomplete observation. J Am Stat Assoc 53: 457-481

Komoike Y, Akiyama F, Ino Y, Ikeda T, Tanaka-Akashi S, Ohsumi S, Kusama M, Sano M, Shin E, Suemasu K, Sonoo H, Taguchi T, Nishi T, Nishimura R, Haga S, Mise K, Kinoshita T, Murakami S, Yoshimoto M, Tsukuma H, Inaji $\mathrm{H}$ (2005) Analysis of ipsilateral breast tumor recurrences after breast-conserving treatment based on the classification of true recurrences and new primary tumors. Breast Cancer 12: 104-111

Kreike B, Halfwerk $\mathrm{H}$, Kristel $\mathrm{P}$, Glas A, Peterse $\mathrm{H}$, Bartelink $\mathrm{H}$, van de Vijver MJ (2006) Gene expression profiles of primary breast carcinomas from patients at high risk for local recurrence after breast-conserving therapy. Clin Cancer Res 12: 5705-5712

Kuukasjarvi T, Karhu R, Tanner M, Kahkonen M, Schaffer A, Nupponen N, Pennanen S, Kallioniemi A, Kallioniemi OP, Isola J (1997) Genetic heterogeneity and clonal evolution underlying development of asynchronous metastasis in human breast cancer. Cancer Res 57: 1597-1604

Millis RR, Barnes DM, Lampejo OT, Egan MK, Smith P (1998) Tumour grade does not change between primary and recurrent mammary carcinoma. Eur J Cancer 34: 548-553

Nuyten DS, Kreike B, Hart AA, Chi JT, Sneddon JB, Wessels LF, Peterse HJ, Bartelink H, Brown PO, Chang HY, van de Vijver MJ (2006) Predicting a local recurrence after breast-conserving therapy by gene expression profiling. Breast Cancer Res 8: R62

Oh JL, Bonnen M, Outlaw ED, Schechter NR, Perkins GH, Strom EA, Babiera G, Oswald MJ, Allen PK, Thames HD, Buchholz TA (2006) The 
impact of young age on locoregional recurrence after doxorubicin-based breast conservation therapy in patients 40 years old or younger: how young is 'young'? Int J Radiat Oncol Biol Phys 65: 1345-1352

Robbins P, Pinder S, de Klerk N, Dawkins H, Harvey J, Sterrett G, Ellis I, Elston C (1995) Histological grading of breast carcinomas : a study of interobserver agreement. Hum Pathol 26: 873-879

Schlechter BL, Yang Q, Larson PS, Golubeva A, Blanchard RA, de las Morenas A, Rosenberg CL (2004) Quantitative DNA fingerprinting may distinguish new primary breast cancer from disease recurrence. J Clin Oncol 22: $1830-1838$

Shibata A, Tsai YC, Press MF, Henderson BE, Jones PA, Ross RK (1996) Clonal analysis of bilateral breast cancer. Clin Cancer Res 2: 743-748

Smith TE, Lee D, Turner BC, Carter D, Haffty BG (2000) True recurrence $v s$ new primary ipsilateral breast tumor relapse: an analysis of clinical and pathologic differences and their implications in natural history, prognoses, and therapeutic management. Int J Radiat Oncol Biol Phys 48: $1281-1289$

Sobin LH, Wittekind C (2002) TNM Classification of Malignant Tumours. New-York: Wiley-Liss

Teixeira MR, Pandis N, Bardi G, Andersen JA, Heim S (1996) Karyotypic comparisons of multiple tumorous and macroscopically normal surrounding tissue samples from patients with breast cancer. Cancer Res 56: $855-859$

Touboul E, Buffat L, Belkacemi Y, Lefranc JP, Uzan S, Lhuillier P, Faivre C, Huart J, Lotz JP, Antoine M, Pene F, Blondon J, Izrael V, Laugier A, Schlienger M, Housset M (1999) Local recurrences and distant metastases after breast-conserving surgery and radiation therapy for early breast cancer. Int J Radiat Oncol Biol Phys 43: 25-38

van der Sijp JR, van Meerbeeck JP, Maat AP, Zondervan PE, Sleddens HF, van Geel AN, Eggermont AM, Dinjens WN (2002) Determination of the molecular relationship between multiple tumors within one patient is of clinical importance. J Clin Oncol 20: 1105-1114 van Tilborg AA, de Vries A, de Bont M, Groenfeld LE, van der Kwast TH, Zwarthoff EC (2000) Molecular evolution of multiple recurrent cancers of the bladder. Hum Mol Genet 9: 2973-2980

Veronesi U, Marubini E, Del Vecchio M, Manzari A, Andreola S, Greco M, Luini A, Merson M, Saccozzi R, Rilke F, Salvadori B (1995) Local recurrences and distant metastases after conservative breast cancer treatments: partly independent events. J Natl Cancer Inst 87: 19-27

Vicini FA, Antonucci JV, Goldstein N, Wallace M, Kestin L, Krauss D, Kunzmann J, Gilbert S, Schell S (2007) The use of molecular assays to establish definitively the clonality of ipsilateral breast tumor recurrences and patterns of in-breast failure in patients with early-stage breast cancer treated with breast-conserving therapy. Cancer 109: 1264-1272

Vincent-Salomon A, Rousseau A, Jouve M, Beuzeboc P, Sigal-Zafrani B, Freneaux P, Rosty C, Nos C, Campana F, Klijanienko J, Al Ghuzlan A, Sastre-Garau X (2004) Proliferation markers predictive of the pathological response and disease outcome of patients with breast carcinomas treated by anthracycline-based preoperative chemotherapy. Eur J Cancer 40: $1502-1508$

Vrieling C, Collette L, Fourquet A, Hoogenraad WJ, Horiot JC, Jager JJ, Bing Oei S, Peterse HL, Pierart M, Poortmans PM, Struikmans H, Van den Bogaert W, Bartelink H (2003) Can patient-, treatment- and pathologyrelated characteristics explain the high local recurrence rate following breast-conserving therapy in young patients? Eur J Cancer 39: 932-944

Waldman FM, DeVries S, Chew KL, Moore II DH, Kerlikowske K, Ljung BM (2000) Chromosomal alterations in ductal carcinomas in situ and their in situ recurrences. J Natl Cancer Inst 92: 313-320

Whelan T, Clark R, Roberts R, Levine M, Foster G (1994) Ipsilateral breast tumor recurrence postlumpectomy is predictive of subsequent mortality: results from a randomized trial. Investigators of the Ontario Clinical Oncology Group. Int J Radiat Oncol Biol Phys 30: 11-16 